\title{
ANÁLISE DO CONTEÚDO DE CREATINA NO MÚSCULO ESQUELÉTICO DE RATOS SUBMETIDOS A NATAÇÃO E/OU SUPLEMENTAÇÃO DE CREATINA, ATRAVÉS DA ESPECTROSCOPIA INFRAVERMELHA
}

\section{ANALYSIS OF THE CREATINE CONTENT IN THE SKELETAL MUSCLE OF RATS AFTER SWIMMING AND/OR CREATINE SUPPLEMENTATION, THROUGH INFRARED SPECTROSCOPY}

\author{
Vanessa Rezende Leite ${ }^{1}$ \\ Patrícia Marcondes dos Santos ${ }^{2}$ \\ Gabriela do Carmo Silveira ${ }^{3}$ \\ Tayara Pereira Dias ${ }^{3}$ \\ Mituo Uehara ${ }^{4}$ \\ Kumiko Koibuchi Sakane ${ }^{4}$ \\ Rodrigo Lazaro Osório ${ }^{5}$ \\ Antônio Carlos Guimarães Prianti Júnior ${ }^{5}$ \\ Wellington Ribeiro ${ }^{5}$
}

RESUMO: Este estudo foi realizado através de experimentação animal, com duração de nove semanas, no qual os animais foram submetidos a treinamento físico aeróbico e/ou suplementação de creatina (Cr). Os animais foram divididos em oito grupos: um grupo controle sedentário, um grupo controle treinado, três grupos treinados suplementados com três doses diferentes de $\mathrm{Cr}$ e três grupos sedentários suplementados também com três doses diferentes de Cr. Foram analisados 40 espectros de amostras do músculo tibial anterior através de espectroscopia infravermelha. O cálculo da área relativa da banda de Cr no tecido mostrou que existe uma dosagem ótima na suplementação de creatina e que exercício favorece a presença de creatina no músculo.

Palavras-chave: espectroscopia infravermelha; suplementação de creatina; FT-IR; ratos; músculo esquelético.

ABSTRACT: This study was made through a nine-week animal experiment in which animals had aerobic exercise training and/or creatine ( $\mathrm{Cr}$ ) supplementation. The animals were divided into eight groups: one sedentary control group; one training control group; three groups of animals undergoing training with three different doses of $\mathrm{Cr}$, and three sedentary groups also supplemented with three different doses of Cr. Forty spectra with samples of the tibialis anterior muscle were analyzed through infrared spectroscopy. The calculation of the area, relative to the $\mathrm{Cr}$ band in the tissue, indicated that an optimal dose of creatine supplementation and physical exercise promotes the presence of creatine in the muscle.

Keywords: infrared spectroscopy; creatine supplementation; FT-IR; rats; skeletal muscle.

\footnotetext{
${ }^{1}$ Mestranda em Bioengenharia - UNIVAP.

E-mail: varel.e@hotmail.com

${ }^{2}$ Doutoranda em Engenharia Biomédica - UNIVAP.

E-mail: patriciams@univap.br

${ }^{3}$ Graduanda em Ciências Biológicas - UNIVAP.

${ }^{4}$ Professor da UNIVAP - Laboratório de Espectroscopia no Infravermelho - LENIR / IP\&D - UNIVAP.

E-mail: kumiko@univap.br

${ }^{5}$ Professor da UNIVAP - Laboratório de Fisiologia e Farmacodinâmica / IP\&D - UNIVAP.

E-mails: ralo@univap.br; prianti@univap.br; gton@univap.br
} 


\section{INTRODUÇÃO}

A creatina (ácido a-metilguanidino acético) é uma amina de ocorrência natural no organismo humano, sintetizada no fígado, rins e pâncreas a partir dos aminoácidos glicina, arginina e metionina (WALKER,1979). Também é obtida, através da dieta, pelo consumo de carne vermelha, peixes e outros produtos de origem animal (McARDLE et al., 2001). A Cr é distribuída nos diferentes tecidos corpóreos, incluindo coração, cérebro, pulmões, testículos, fígado, rins e principalmente músculos esqueléticos (IPSIROGLU et al., 2001). Cerca de $95 \%$ da $\mathrm{Cr}$ orgânica está armazenada no músculo esquelético. A função primária da $\mathrm{Cr}$ ocorre através da molécula de fosfocreatina, que fornece energia para reconstituir a ligação de alta energia do ATP (GUYTON; HALL, 2010).

Muitos estudos têm investigado o papel da creatina em diversas situações, como: uso como recurso ergogênico para potencializar o desempenho físico de atletas (ELLENDER; LINDER, 2005); após longos períodos de imobilização (OP'T EINJNDE et al., 2001); doenças do sistema musculoesquelético (HURLBERT et al., 1999); doenças endocrinometabólicas (STUART et al., 2009; LAURITZEN et al., 2008); estudos da atividade miocárdica (NAKAE et al., 2003) e de patologias neurológicas como a Doença de Alzheimer (GALLANT et al., 2006). Desde 1994 Greenhaff et al. já haviam sugerido que o aumento da concentração de $\mathrm{Cr}$ na fibra muscular poderia melhorar a capacidade de suportar a fadiga pelo músculo nas atividades de alta intensidade e curta duração. Entretanto, a literatura apresenta poucas discussões a respeito da relação entre a suplementação de $\mathrm{Cr}$ e a atividade física de longa duração (LEMON, 2002).

A técnica de espectroscopia no infravermelho recentemente vem sendo utilizada em estudos de tecidos biológicos (BARTH, 2007). O espectro infravermelho de sistemas biológicos é resultante da contribuição das bandas de absorção ativas no infravermelho de todas as biomoléculas que constituem o tecido biológico (STUART, 1997). Assim, a diferenciação entre espectros através apenas da inspeção visual direta torna-se, às vezes inviável, levando a necessidade de se recorrer a métodos matemáticos para se obterem informações estruturais mais complexas. $O$ objetivo deste estudo foi avaliar se a técnica de espectroscopia no infravermelho pode ser útil no estudo da quantificação de $\mathrm{Cr}$ armazenada no tecido musculoesquelético de ratos treinados e/ou suplementados com $\mathrm{Cr}$, visando demonstrar se há diferenças na impregnação de $\mathrm{Cr}$ no tecido muscular de acordo com a administração oral de três doses diferentes de $\mathrm{Cr}$ e qual seria a melhor dose a ser utilizada.

\section{MATERIAL E MÉTODOS}

Após aprovação do projeto de pesquisa enviado à Comissão de Ética em Pesquisa com Animais/IP\&D (Instituto de Pesquisa e Desenvolvimento)/UNIVAP (A05/CEAU/2010), iniciou-se este estudo com 48 ratos Wistar adultos jovens, fêmeas, com peso entre 200 e 300 gramas, mantidos no biotério do Laboratório de Fisiologia e Farmacodinâmica do IP\&D/UNIVAP, de acordo com os princípios éticos preconizados pelo Colégio Brasileiro de 
Experimentação Animal (COBEA), descritos por Cardoso (2004), submetidos a ciclo claro-escuro de 12 horas, temperatura de $22{ }^{\circ} \mathrm{C}$ a $25^{\circ} \mathrm{C}$, umidade de $40 \%$ a $60 \%$, sendo alimentados com água e ração $a d$ libitum. Os animais foram distribuídos em oito grupos, com seis animais por grupo, conforme relacionado abaixo:

- Grupo 1 (G1): Controle sedentário; animais sedentários que receberam dieta restrita a água e ração balanceada comercial.

- Grupo 2 (G2): Controle treinado; animais treinados que receberam dieta restrita a água e ração balanceada.

- Grupo 3 (G3): animais sedentários que receberam suplementação de creatina $(0,15 \mathrm{~g} / \mathrm{kg})$, além da dieta normal.

- Grupo 4 (G4): animais sedentários que receberam suplementação de creatina $(0,30 \mathrm{~g} / \mathrm{kg})$, além da dieta normal.

- Grupo 5 (G5): animais sedentários que receberam suplementação de creatina $(0,50 \mathrm{~g} / \mathrm{kg})$, além da dieta normal.

- Grupo 6 (G6): animais treinados que receberam suplementação de creatina $(0,15 \mathrm{~g} / \mathrm{kg})$, além da dieta normal.

- Grupo 7 (G7): animais treinados que receberam suplementação de creatina $(0,30 \mathrm{~g} / \mathrm{kg})$, além da dieta normal

- Grupo 8 (G8): animais treinados que receberam suplementação de creatina $(0,50 \mathrm{~g} / \mathrm{kg})$, além da dieta normal.

\subsection{Protocolo Experimental}

Os animais dos grupos G2, G6, G7 e G8 cumpriram um período de adaptação durante cinco dias por semana ao longo de duas semanas em sessões de natação sem carga, durante 30 minutos por dia.

Após este período iniciou-se a suplementação de $\mathrm{Cr}$ e o treinamento físico, com duração de sete semanas. A suplementação foi feita por via oral com auxílio de agulha de gavagem, diariamente e sempre no mesmo horário (30 minutos antes da sessão de treinamento físico). $\mathrm{Na}$ primeira semana de suplementação (Fase de Carregamento) as doses de creatina foram: 0,15 g/kg para os grupos G3 e G6; $0,30 \mathrm{~g} / \mathrm{kg}$ (BRANNON et al., 1997) para os grupos G4 e G7; 0,50 g/kg (McBRIDE et al., 2002) para os grupos G5 e G8. Nas sete semanas seguintes (Fase de Manutenção) as doses utilizadas foram correspondentes a um quarto das doses de carregamento (BUFORD et al., 2007; BEMBEN; LAMONT, 2005; VOLEK; RAWSON, 2004), ou seja: 0,035 g/kg para os grupos G3 e G6; 0,075 $\mathrm{g} / \mathrm{kg}$ para os grupos G4 e G7; 0,125 g/kg para os grupos G5 e G8.

Os grupos G2, G6, G7 e G8 foram submetidos a treinamento físico de resistência durante sete semanas, realizado através de sessões de natação (30 minutos/dia durante 5 dias por semana, de segunda a sexta-feira, sempre no mesmo horário, no período da tarde). O treinamento foi feito com sobrecarga de $80 \%$ da carga máxima suportada por cada animal. A carga máxima foi determinada através de um Teste de Carga Máxima (OSORIO et al., 2003a).

\subsection{Protocolo de Anestesia, Procedimento Cirúrgico e Sacrifício dos Animais}

Após as sete semanas os animais foram submetidos a anestesia inalatória para 
a execução de procedimento cirúrgico e o agente anestésico utilizado foi o halotano (BARASH, 2009). Com os animais anestesiados foi realizada a ressecção do músculo tibial anterior esquerdo. Em seguida, os animais foram eutanaziados, ainda sob anestesia, através de injeção intracardíaca de cloreto de potássio $(\mathrm{KCl})$ a $20 \%$. As amostras do tecido muscular foram liofilizadas e mantidas a temperatura de aproximadamente $-20^{\circ} \mathrm{C}$ até a análise.

\subsection{Obtenção dos Espectros de Absorção Infravermelha}

Foi utilizada uma amostra do tecido muscular liofilizado de um animal de cada grupo para a obtenção dos espectros infravermelhos. As amostras foram submetidas a liofilização por 20 horas. Após este processo, foram confeccionadas oito pastilhas de brometo de potássio $(\mathrm{KBr})$ com a concentração de $1 \mathrm{mg}$ de tecido muscular em 150mg de $\mathrm{KBr}$; correspondentes à amostra de cada um dos oito grupos estudados.

Foram obtidos cinco espectros de cada amostra, num total de quarenta espectros, na faixa de 4000 a $850 \mathrm{~cm}^{-1}$, com resolução de $4 \mathrm{~cm}^{-1}$, no modo de transmissão, com 32 varreduras a temperatura controlada $\left(18\right.$ a $\left.20^{\circ} \mathrm{C}\right)$. O espectrofotômetro utilizado foi o Spectrum GX FT-IR da PerkinElmer. Os espectros foram pré-processados com o software Spectrum 5.3 (PerkinElmer), onde foram feitas as correções de linha de base, suavização espectral através do algoritmo Savistzky Golay (9 pontos) e normalização.

Os espectros foram analisados através de dois métodos: 1. Inspeção visual direta e 2. Cálculo da área relativa da banda de creatina.

\section{RESULTADOS E DISCUSSÃO}

$\mathrm{Na}$ inspeção visual direta, observou-se que os oito espectros (Figs. 1, 2 e 3) são muito semelhantes, não sendo possível apontar diferenças visuais importantes entre eles. Com base no espectro médio da amostra do grupo G1, a Tabela 1 apresenta as regiões em que se encontram as bandas características de biomoléculas do tecido muscular e suas atribuições aproximadas (STUART, 1997; MANTSCH; CHAPMAN, 1996). Observa-se a predominância das bandas de proteínas, lipídeos e glicose.

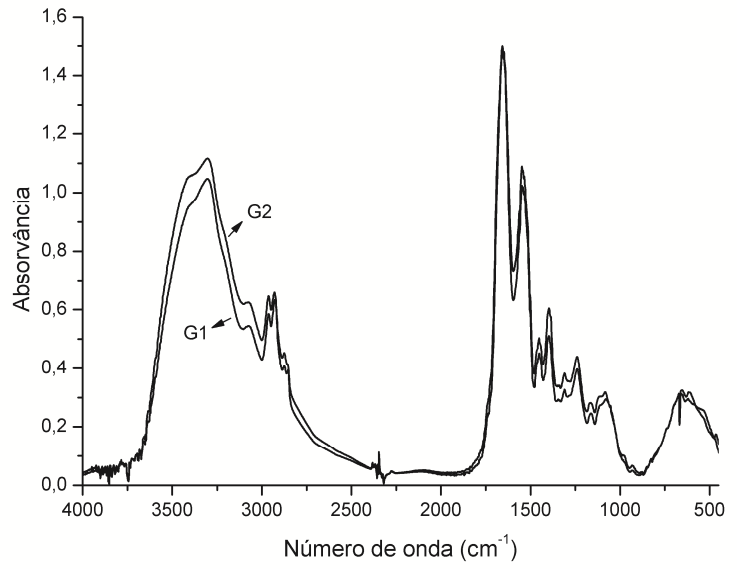

Fig. 1 - Espectros Infravermelhos do tecido muscular de ratos sedentários e treinados sem suplementação de creatina.

Foi realizado o cálculo das áreas relativas entre a área da banda de referência e a área da banda que indica a presença de $\mathrm{Cr}$ no tecido muscular. Buscou-se através desses cálculos encontrar alterações nas 
intensidades das bandas relacionadas aos modos normais de vibração da Cr. Portanto, foi necessário escolher uma banda indicadora da presença de creatina no tecido muscular, chamada de banda marcadora neste processo. Para isto, analisou-se o espectro de creatina pura a fim de identificar a melhor região na busca desta marcadora. A escolha da banda marcadora é importante para a realização dos cálculos e, pode variar de acordo com o tecido estudado. Em

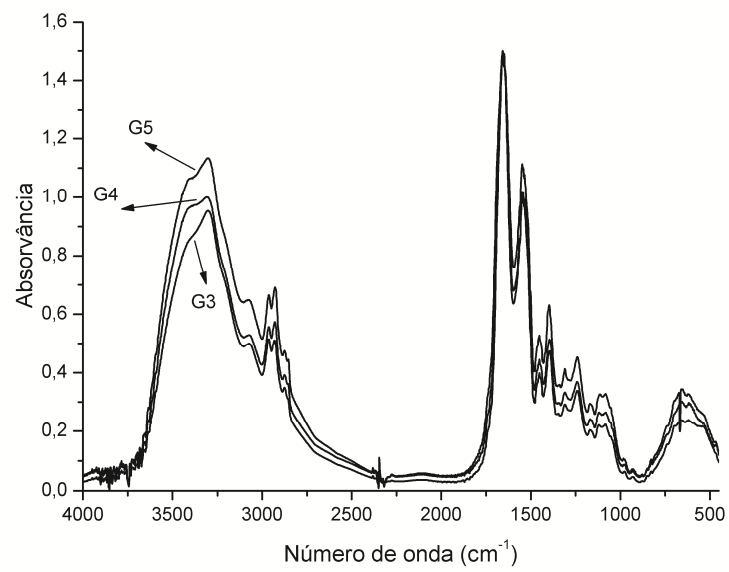

Fig. 2 - Espectros Infravermelhos do tecido muscular de ratos sedentários com suplementação de creatina. estudo de tecido cerebral utilizando técnica de espectroscopia infravermelha, Gallant et al. (2006) analisaram a presença de $\mathrm{Cr}$ no cérebro humano afetado pela Doença de Alzheimer. Estes autores utilizaram a banda de $1304 \mathrm{~cm}^{-1}$ como marcadora de creatina. Em nosso estudo, foi escolhida como marcadora a banda de $1397 \mathrm{~cm}^{-1}$, referente ao modo vibracional de estiramento simétrico, $\mathrm{v}_{\mathrm{COO}}$, de ânion carboxilato, $\mathrm{COO}^{-}$ dos aminoácidos (SILVERSTEIN, 2007).

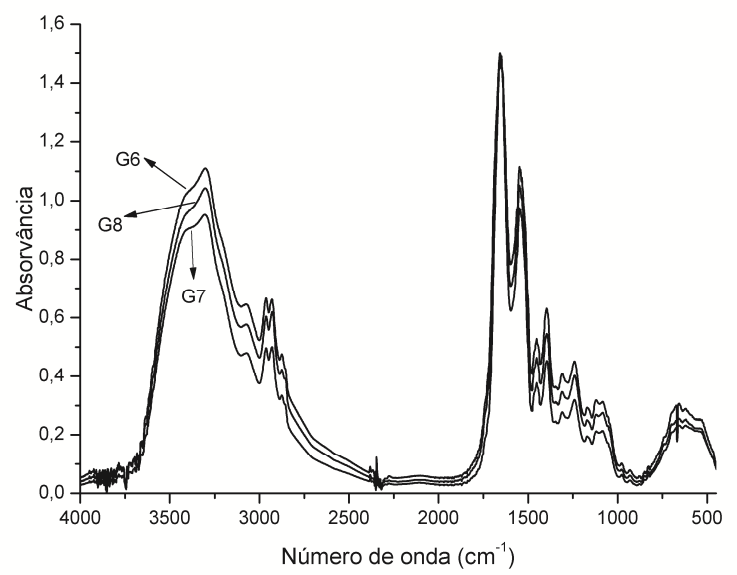

Fig. 3 - Espectros Infravermelhos do tecido muscular de ratos treinados com suplementação de creatina.
Esta escolha foi justificada pela localização desta banda em uma região livre das bandas intensas de amidas I e II de proteínas, podendo assim ser identificada com facilidade no tecido muscular. A Fig. 4 mostra o espectro infravermelho da creatina no estado sólido e a seta indica a banda utilizada como marcadora neste estudo. 
Tabela 1 - Número de onda e descrições aproximadas das bandas do tecido muscular da amostra de grupo 1 (G1)

\begin{tabular}{|c|c|}
\hline Número de onda $\left(\mathrm{cm}^{-1}\right)$ & Modos normais de vibração e suas atribuições \\
\hline \multicolumn{2}{|l|}{ Região 1: 4000 a $3000 \mathrm{~cm}^{-1}$} \\
\hline 3303 & estiramento da ligação O-H do grupo hidroxila; amida A (proteína) \\
\hline 3072 & amida B (proteína) \\
\hline \multicolumn{2}{|l|}{ Região 2: 3000 a $2800 \mathrm{~cm}^{-1}$} \\
\hline 2961 & estiramento assimétrico do grupo $-\mathrm{CH}_{3}$ (lipídeos) \\
\hline 2926 & estiramento assimétrico do grupo $>\mathrm{CH}_{2}$ (lipídeos) \\
\hline 2874 & estiramento simétrico do grupo $-\mathrm{CH}_{3}$ (lipídeos) \\
\hline 2853 & estiramento simétrico do grupo $>\mathrm{CH}_{2}$ (lipídeos) \\
\hline \multicolumn{2}{|l|}{ Região 3: 1750 a $1500 \mathrm{~cm}^{-1}$} \\
\hline 1734 & estiramento de $\mathrm{C}=\mathrm{O}$ do grupo éster (lipídeos) \\
\hline 1656 & amida I (proteínas) \\
\hline 1648 & amida I (proteínas) \\
\hline 1547 & amida II (proteínas) \\
\hline 1541 & amida II (proteínas) \\
\hline 1535 & amida II (proteínas) \\
\hline 1503 & amino-ácido residual (proteínas) \\
\hline \multicolumn{2}{|l|}{ Região 4: 1500 a $1200 \mathrm{~cm}^{-1}$} \\
\hline 1452 & $\begin{array}{l}\text { deformação angular do grupo }>\mathrm{CH}_{2} \text {; deformação angular assimétrica } \\
\text { do grupo }-\mathrm{CH}_{3} \text { (lipídios) }\end{array}$ \\
\hline \multicolumn{2}{|r|}{ ( } \\
\hline 1397 & estiramento simétrico de $\mathrm{COO}^{-}$(aminoácidos) \\
\hline \multicolumn{2}{|l|}{1345} \\
\hline \multicolumn{2}{|l|}{1309} \\
\hline 1239 & $\begin{array}{l}\text { amida III (proteínas); estiramento assimétrico do } \mathrm{PO}_{2}{ }^{-} \text {do fosfodiester } \\
\text { (fosfolipídios) }\end{array}$ \\
\hline \multicolumn{2}{|l|}{ Região 5: 1200 a $850 \mathrm{~cm}^{-1}$} \\
\hline 1162 & estiramento de ligação C-O do anel de polissacarídios \\
\hline 1109 & estiramento de ligação C-O do anel de polissacarídios \\
\hline 1079 & $\begin{array}{l}\text { estiramento simétrico de } \mathrm{PO}_{2}^{-} \text {do fosfodiester (fosfolipídios); } \\
\text { estiramento de ligação } \mathrm{C}-\mathrm{O} \text { do anel de polissacarídios }\end{array}$ \\
\hline 933 & estiramento de ligação C-O do anel de polissacarídios \\
\hline
\end{tabular}

Fonte: STUART, 1997; MANTSCH; CHAPMAN, 1996.

Como a área de uma banda se relaciona com a população, a área da banda de $1397 \mathrm{~cm}^{-1}$ foi calculada no intervalo de 1426 a $1356 \mathrm{~cm}^{-1}$ com o software Spectrum 5.3. Em seguida, foi comparada à área da banda de $1239 \mathrm{~cm}^{-1}$, atribuída principalmente como amida III da proteína (STUART, 1997; MANTSCH; CHAPMAN, 1996; TWARDOWSKI; ANZENBACHHER,
1994), calculada no intervalo de 1275 a 1183 $\mathrm{cm}^{-1}$. Esta banda de amida III foi escolhida como de referência porque a creatina não possui bandas intensas nesta região. Este procedimento foi repetido para espectros médios de oito grupos. Os resultados dos cálculos das áreas relativas estão apresentados na Tabela 2 e na Fig. 5. 


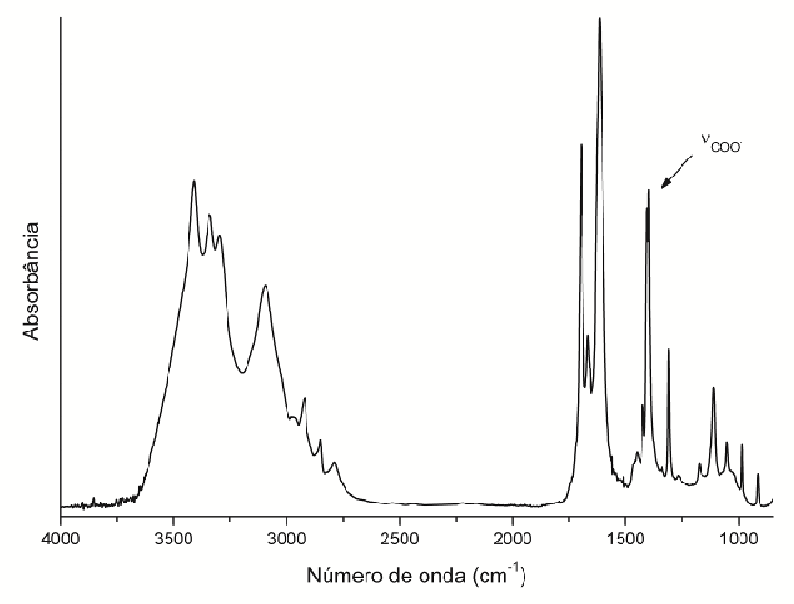

Fig. 4 - 0 espectro infravermelho de creatina.

Tabela 2 - Cálculo de áreas relativas, $A_{1397} / A_{1239}$

\begin{tabular}{cc}
\hline Grupos & $\mathbf{A}_{\mathbf{1 3 9 7}} / \mathbf{A}_{\mathbf{1 2 3 9}}$ \\
\hline Grupo 1 (G1) & 0,82544 \\
Grupo 2 (G2) & 1,0329 \\
Grupo 3 (G3) & 1,0508 \\
Grupo 4 (G4) & 1,0433 \\
Grupo 5 (G5) & 1,0184 \\
Grupo 6 (G6) & 1,0499 \\
Grupo 7 (G7) & 1,5692 \\
Grupo 8 (G8) & 1,5232 \\
\hline
\end{tabular}

A Fig. 5 sugere que há uma dosagem ótima de suplementação de creatina (que neste trabalho, corresponde àquela utilizada pelos humanos) e que 0 exercício favorece a presença de creatina no músculo.

Observaram-se diferenças importantes nas áreas relativas da banda de creatina entre o grupo controle sedentário (G1) e os demais grupos. Estas diferenças se concentraram em dois patamares distintos, como se pode ver na Fig. 5. O grupo controle treinado (G2), os grupos sedentários suplementados (G3, G4 e G5) e o grupo treinado suplementado com a menor dose de $\mathrm{Cr}$ (G6) permaneceram englobados num primeiro patamar, onde se veem aumentos da área relativa da banda de $\mathrm{Cr}$ que vão de 23,4\% (G5) a 27,3\% (G3), em relação ao grupo controle sedentário (G1). 


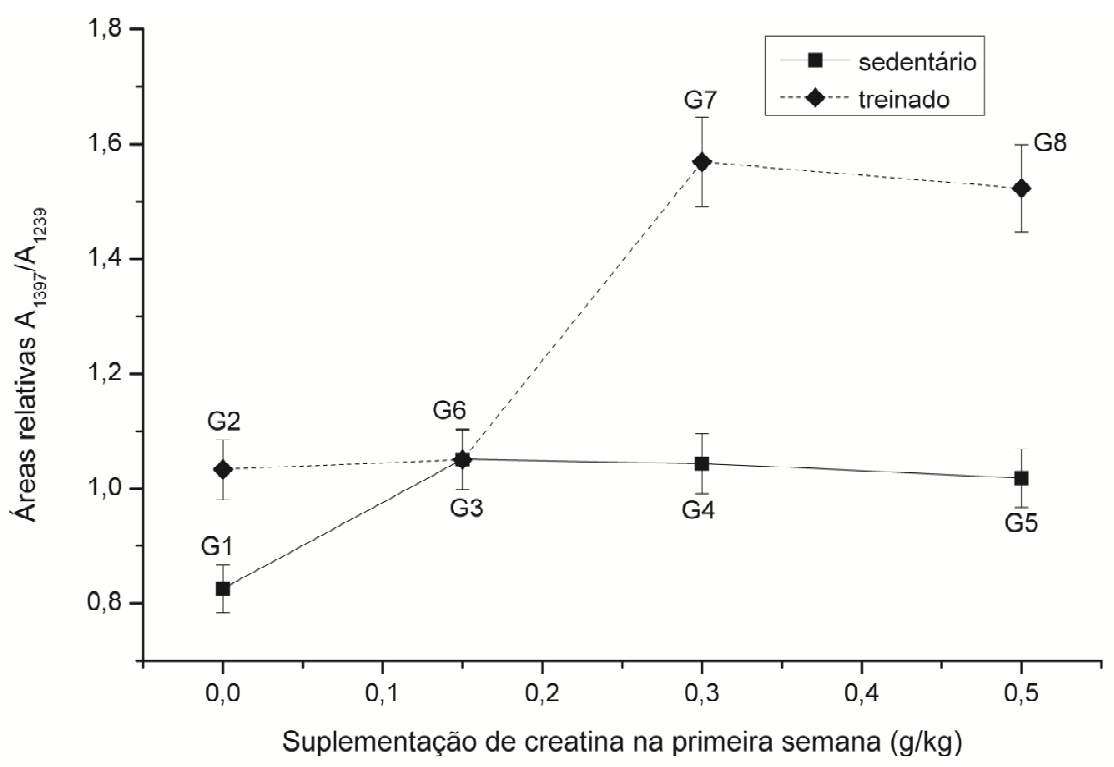

Fig. 5 - Alteração da creatina em função da dose de suplementação e do treinamento físico.

Num segundo patamar do gráfico (Fig. 5) estão alocados os grupos treinados e suplementados com a dose média de $\operatorname{Cr}(0,3$ $\mathrm{g} / \mathrm{kg} / \mathrm{dia})$ e com a dose máxima de $\operatorname{Cr}(0,5$ g/kg/dia), G7 e G8, respectivamente.

É interessante observar que o grupo sedentário G5, apesar de ter sido suplementado com a maior dose de $\mathrm{Cr}(0,50$ $\mathrm{g} / \mathrm{kg} / \mathrm{dia}$ ), não apresentou maior aumento da área relativa da banda de $\mathrm{Cr}$ em relação ao grupo controle treinado (G2) e também em relação aos outros grupos situados neste patamar do gráfico.

Outra observação deve ser feita em relação ao grupo treinado $\mathrm{G} 8$, que, apesar de ter sido suplementado também com a maior dose de $\operatorname{Cr}(0,50 \mathrm{~g} / \mathrm{kg} / \mathrm{dia})$, não apresentou maior aumento $(84,5 \%)$ da área relativa da banda de $\mathrm{Cr}$, em relação ao grupo treinado G7, que recebeu a dose média de $\mathrm{Cr}(0,30$ $\mathrm{g} / \mathrm{kg} / \mathrm{dia}$ ), o qual apresentou o maior aumento da área relativa da banda de $\operatorname{Cr}(90,1 \%)$.
Estes resultados remetem a considerações a respeito da farmacodinâmica e farmacocinética da $\mathrm{Cr}$. De fato, é relatado que o exercício por si só, é efetivo em aumentar a captação de $\mathrm{Cr}$ pelo tecido muscular (GUYTON; HALL, 2010; THORELL et al., 1999; HARRIS et al., 1992). Isto poderia explicar a alteração ocorrida no grupo controle treinado, sem suplementação de $\mathrm{Cr}$ (G2). A natação como modelo de atividade física em ratos é amplamente descrita na literatura (THEODOROU et al., 2005; MORIFUGI et al., 2005; ANOMARISI et al., 2004). Neste estudo foi utilizado um protocolo de treinamento de resistência aeróbica, já empregado por Souza (2006), no qual a carga de trabalho foi ajustada individualmente a $80 \%$ da carga máxima suportada por cada animal. Segundo Franco (2004), Sampaio-Barros et al. (2003) e Viru (1994), nesta faixa de treinamento os animais desempenhariam atividade física 
com predomínio metabólico aeróbico.

Também deve-se lembrar que os tecidos apresentam uma capacidade máxima de armazenamento para a $\mathrm{Cr}$ e que a saturação do tecido ocorre na fase de carregamento, quando se utiliza uma dose bem maior do suplemento (IPSIROGLU et al., 2001). A revisão da literatura (BUFORD et al., 2007; BEMBEN; LAMONT, 2005; VOLEK; RAWSON, 2004) evidencia que a maioria dos estudos em humanos com a suplementação de $\mathrm{Cr}$, dividem o experimento em duas fases: (1) Fase de Carregamento, na qual se administra uma dose elevada de $\mathrm{Cr}$ (20 a 30g/dia) por 5 a 7 dias e (2) Fase de Manutenção, na qual se utiliza uma dose que corresponde geralmente a $1 / 5$ da dose inicial, ao longo de várias semanas.

O determinante mais forte de quanta $\mathrm{Cr}$ é captada pelo tecido muscular após a suplementação seria o teor inicial de $\mathrm{Cr}$ no músculo, segundo Harris et al. (1992) e Hultman et al. (1996). Indivíduos com estoque mais baixo de $\mathrm{Cr}$ muscular teriam maior aumento dela após a suplementação (RAWSON et al., 2002). Entretanto, talvez a associação da suplementação de $\mathrm{Cr}$ ao treinamento físico possa promover adaptações teciduais mais acentuadas, conforme já foi investigado por vários autores (BUFORD et al., 2007; BRANCH, 2003; ARCIERO et al., 2001).

É válido lembrar que a suplementação de $\mathrm{Cr}$, a longo prazo, pode estimular o mecanismo de regulação lenta (down regulation) dos receptores de $\mathrm{Cr}$, impedindo a captação adicional deste nutriente pelo tecido muscular (GUERRERO-ONTIVEROS; WALLIMAN, 1998). Então, a longo prazo, a suplementação de $\mathrm{Cr}$ aumentaria as concentrações deste composto em tecidos que apresentam valores basais muito baixos de $\mathrm{Cr}$ celular, como o fígado e os rins (IPSIROGLU et al., 2001). Também existem evidências de que a captação de $\mathrm{Cr}$ pelo tecido muscular possa ser influenciada por outros fatores. ODOOM et al. (1996) verificaram que os hormônios triiodotironina (T3), fator de crescimento similar a insulina (IGF-1) e insulina foram responsáveis por aumentar o conteúdo de creatina total em células musculares de ratos.

Em se tratando de estudo realizado em animais (ratos), são encontrados na literatura vários protocolos para suplementação de Cr. Isto pode ser justificado pelo fato de que estes animais apresentam taxa de metabolismo basal, conversão e assimilação de compostos orgânicos bem mais intensos (IPSIROGLU et al., 2001). Brannon et al. (1997) avaliaram o efeito da suplementação de $\mathrm{Cr}$ com doses de $252 \pm 8 \mathrm{mg} / \mathrm{kg}$ ao longo de 10 dias e verificaram aumento do conteúdo de Cr livre e na sua forma fosforilada nos músculos sóleo e plantar de ratos. Op't Eijnde et al. (2001a) administraram altas doses de $\mathrm{Cr}$ (dissolvida a $5 \%$ na ração) para ratos por 5 dias. Ju et al. (2005) suplementaram ratos com $\mathrm{Cr}$ dissolvida a $2 \%$ na ração durante 3 semanas. McBride et al. (2002) observaram o efeito da suplementação de $\mathrm{Cr}$ com dose de $500 \mathrm{mg} / \mathrm{kg} / \mathrm{dia}$ por 4 semanas. Com base nos experimentos desses autores, nosso estudo utilizou um protocolo de suplementação de $\mathrm{Cr}$ com três doses diferentes.

Portanto, de acordo com os resultados apresentados, pode-se ponderar que as repercussões da suplementação de $\mathrm{Cr}$ no músculo tibial anterior dos animais deste 
estudo parecem ter sido dependentes de fatores citados na literatura, como a concentração tecidual inicial de $\mathrm{Cr}$, o protocolo de suplementação utilizado e o treinamento físico instituído, dentre outros.

Muitas técnicas laboratoriais têm sido utilizadas na avaliação do conteúdo de creatina nos tecidos, tais como: cromatografia gasosa, cromatografia líquida de alta eficiência, espectrometria de massa e espectrometria por ressonância magnética (NICOLIN et al., 2004; KLASS, 2003). O uso da técnica de espectroscopia infravermelha na avaliação do conteúdo de $\mathrm{Cr}$ nos tecidos orgânicos ainda é recente e escasso (GALLANT et al., 2006). Neste estudo, a técnica de espectroscopia infravermelha se mostrou com características de alta precisão e rapidez, sendo capaz de demonstrar resultados compatíveis com a literatura utilizando quantidades muito pequenas de amostras teciduais. Isto nos faz acreditar que possa ser útil também em estudos com humanos.

\section{CONCLUSÃO}

De acordo com os resultados deste estudo, concluímos que a Técnica de Espectroscopia Infravermelha apresenta potencial de uso para a quantificação de creatina no tecido musculoesquelético de ratos submetidos a treinamento físico e/ou suplementação de creatina a longo prazo.

Os espectros infravermelhos indicam a existência de uma dosagem ótima na suplementação da creatina e que o exercício físico favorece a presença de creatina no músculo.

\section{AGRADECIMENTOS}

Patrícia Marcondes dos Santos agradece a bolsa de estudos concedida pela Fundação Valeparaibana de Ensino.

\section{REFERÊNCIAS BIBLIOGRÁFICAS}

ANOMARISI, W.; SANGUANRUNGSIRIKUL, S.; SAICHANDEE, P. Low dose creatine supplementation enhances sprint phase of 400 meters swimming performance. J. Med. Assoc. Thai., v. 87, n. 2, p. 228-232, 2004.

ARCIERO, P. J. et al. Comparison of creatine ingestion and resistance training on energy expenditure and limb blood flow. Metabolism, v. 50, n. 1, p. 429-535, 2001.

BARASH, P. G.; CULLEN, B. F.; STOELTING, R. K. Clinical Anesthesia. Philadelphia, Pa, USA. Lippincott Williams \& Wilkins, 2009. 423p.

BARTH, A. Infrared spectroscopy of proteins, Biochimica et Biophysica Acta, v. 1767, p. 1073-1101, 2007.

BEMBEN, M. G.; LAMONT, H. S. Creatine supplementation and exercise performance: recent findings. Sports Med., v. 35, n. 2, p. 107-125, 2005.

BRANNON, T. A. et al. Effects of creatine loading and training on running performance and biochemical properties of rat skeletal muscle. Med Sci, v. 29, p. 489-495, 1997.

BRANCH, J. D. Effect of creatine supplementation on body composition and performance: a meta-analysis. Int. J. Sport Nutr. Exerc. Metab., v. 13, p. 198-226, 2003.

BUFORD, T. W. et al. International Society of 
Sports Nutrition position stand: creatine and exercise. Journal of the International of Society of Sports Nutrition, v. 4, p. 6, 2007.

CARDOSO, C. V. P. Princípios Éticos na Experimentação Animal. Disponível em: http://www.cobea.org.br/etica.htm\#3.

Acessado em: 21 ago. 2009.

ELLENDER, L.; LINDER, M. M. Sports pharmacology and ergogenic aids. Prim. Care., v. 32, n. 1, p. 277-292, 2005.

FRANCO, A. D. Avaliação dos níveis plasmáticos das substâncias reativas ao ácido tiobarbitúrico e da atividade das enzimas antioxidantes nos eritrócitos de ratos Wistar submetidos a diferentes intensidades relativas do treinamento com natação. 2004. 73f. Dissertação (Mestrado em Ciências Biológicas). Instituto de Pesquisa e Desenvolvimento da Universidade do Vale do Paraíba, São José dos Campos, 2004.

GALLANT, M. et al.Focally elevated creatine detected in amyloid precursor protein(APP) transgenic mice and Alzheimer disease brain tissue. Journal of Biological Chemistry, v. 281, p. 5-8, 2006

GUERRO-ONTIVEROS, M. L.; WLLIMANN, T. Creatine supplementation in health and disease. Effects of chronic creatine ingestion in vivo: downregulation of the expression of creatine transporter isoforms in skeletal muscle. Mol Cell Biochem, v. 184, p. 427437, 1998.

GREENHAFF, P. L. The nutritional biochemistry of creatine. Journal of Nutritional Biochemistry. v. 11, p. 610-618, 1997.

GUYTON, A. C.; HALL, J. E. Tratado de
Fisiologia Médica. Rio de Janeiro: Elsevier, 2010. 41p.

HARRIS, R. C.; SODERLUND, K.; HULTMAN, E. Elevation of creatine in resting and exercised muscle of normal subjects by creatine supplementation. Clin Sci, v. 83, p. 367-374, 1992.

HULTMAN, E. et al. Muscle creatine loading in mem. J. Appl.Physiol., v. 81, p. 232-237, 1996.

HURLBERT, M. S. et al. Mice transgenic for an expanded CAG repeat in the Huntigton's disease gene develop diabetes. Diabetes, v. 48 , p. 649-651, 1999.

IPSIROGLU, S. O. et al. Changes of tissue creatine concentrations upon oral supplementation of creatine-monohydrate in various animal species. Life Science. v. 69, n. 15, p. 1805-1815, 2001.

JU, J. S. et al. Creatine feeding increases GLUT4 expression in rat skeletal muscle. Am J Physiol Endocrinol Metab., v. 288, p. E347-E352, 2005.

KLAAS, W. et al. MR Spectroscopy of muscle and brain in guanidinoacetate methyltransferase(GAMT) deficient mice: validation of an animal model to study creatine deficiency. Magn. Reson. Med., v. 50, n. 5, p. 936-943, 2003.

LAURITZEN, H. P. et al. Large GLUT4 vesicles are stationary while locally and reversibly depleted during transient insulin stimulation of skeletal muscle of living mice:imaging analysis of GLUT4-enhanced green fluorescent protein vesicle dynamics. Diabetes, v. 57, p. 315-324, 2008.

LEMON, P. W. R. Dietary Creatine Supplementation and Exercise Performance: 
Why Inconsistent Results? Can J Appl Physiol, v. 27, p. 663-680, 2002.

MANTSCH, H. H.; CHAPMAN, D. Infrared Spectroscopy ob Biomolecules. John Wiley \& Sons, 1996, 203p.

McARDLE, W. D.; KATCH, V. L. Nutrição para o desporto e o exercício. Rio de Janeiro: Guanabara Koogan, 2001.

MCBRIDE, T. A.; GREGORY, M. A. Effect of creatine supplementation during high resistance training on mass, strength, and fatigue resistance in rat. Skeletal Muscle. J. Strength Cond. Res. v. 16, n. 3, p. 335-342, 2002.

MORIFUGI, $M$ et al. Dietary whey protein downregulates fatty acid synthesis in the liver, but upregulates it in skeletal muscle of exercise-trained rats. Nutrition. v. 21, n. 10, p. 1052-1058, 2005.

NAKAE, I. et al. Proton magnetic resonance spectroscopy can detect creatine depletion associated with the progression of heart failure in cardiomyopathy, Journal of American College of Cardiology, v. 42, p. 1587-1593, 2003.

NICOLIN, B. et al. High performance liquid chromatography in pharmaceutical analyses. Bosn, J. Basic Med. Sci., v. 4, n. 2, p. 5-9, 2004.

ODOOM, J. E.; KEMP, G. J.; RADDA, K. The regulation of total creatine content in myoblast cell line. Mol. Cell. Biochem. v. 158, p. 179-188, 1996.

OP'T EIJNDE, B. et al. Effect of Oral Creatine Supplementation on Human Muscle GLUT4 Protein Content After Immobilization. American Diabetes Association. v. 50, p.
18-23, 2001

OSORIO, R. A. L et al. Swimming of pregnant rats at different water temperatures. Comp. Biochem. Phisiol. A. Mol. Integr. Phisiol., v. 135, n. 4, p. 605-611, 2003.

RAWSON, E. S. et al. Differential response of muscle phosphocreatine to creatine supplementation in young and old subjects. Acta Physiol, Scand., v. 174, p. 57-65, 2002.

SAMPAIO-BARROS, M. M. et al. Effect of swimming session duration and repetition on metabolic markers in rats. Stress. v. 6, n. 2, p. 127-132, 2003.

SILVERSTEIN, R. M.; WEBSTER, F. X.; KIEMLE, D. J. Identificação espectrométrica de compostos orgânicos. 7. ed. Rio de Janeiro: LTC, 2007. 490p.

SOUZA, R. A. Estudo da suplementação aguda e crônica de creatina em ratos sedentários e exercitados - avaliação bioquímica e histomorfológica da função renal e hepática. 2006. 111f. Dissertação (Mestrado em Ciências Biológicas) - Instituto de Pesquisa e Desenvolvimento, Universidade do Vale do Paraíba, São José dos Campos, 2006.

STUART, B. H. Biological Applications of Infrared Spectroscopy. Chichester, New York, John Wiley \& Sons, 1997.

STUART, C. A. et al. Insulin-Stimulated Tranlocation (GLUT) 12 Parallels that of GLUT4 in Normal Muscle. J. Clin. Endocrinol. Metab., v. 94, n. 9, p. 35353542, 2009. 
THEODOROU, A. S. et al. Effects of acute creatine loading with or without carbohydrate on repeated bouts of maximal swimming in high-performance swimmers. J. Strength Cond. Res. v. 19, n. 2, p. 265-269, 2005.

THORELL, A. et al. Exercise and insulin cause GLUT-4translocation in human skeletal muscle. Am J Physiol. v. 277, p. E733-741, 1999.

TWARDOWSKI, J.; ANZENBACHHER, P. Raman and IR Spectroscopy in Biology and Biochemistry. Warsaw. Polish Scientific Publishers, 1994. 269 p.
VIRU, M. Differences in effects of various training regimens on metabolism of skeletal muscles. J Sports Med Phys Fitness. v. 34, n. 3, p. 217-227, 1994.

VOLEK, J. S.; RAWSON, E. S. Scientific basis and practical aspects of creatine supplementation for athletes. Nutrition. v. 20, p. 609-614, 2004.

WALKER, J. B. Creatine: Biosynthesis, Regulation and Function. Adv Enzymol Relat Areas Mol Biol., v. 50, p. 177-242, 1979. 